\title{
Preservation of Cultural Identity through Speech Components in the Southern Coastal Java Environment
}

\author{
Riris Tiani ${ }^{*}$ \\ Faculty of Humanities, Diponegoro University, Semarang - Indonesia
}

\begin{abstract}
This research discusses the form of defence of the southern coastal community which is frequently considered strange by most of the Indonesian archipelago community. The analysis began with discussing the linguistic phenomena of the local community, identifying and corroborating the findings as initial capital to determine the analysis method. The findings can be useful for making corrections or structuring social and cultural policies towards indigenous/local wisdom and preserving cultural identity. The research was oriented to the speech lexicon of the Southern coastal communities of Central Java. This research used descriptive qualitative and contextual approaches. The analysis used to describe the speech component was dialect geography and collaborated with an anthropological-linguistic approach to find innovative forms and factors that maintained local identity. As the southern coastal chain of Central Java, bordering with West Java, the nuances of cultural acculturation as a form of cultural pluralism are very visible. Cultural acculturation results in the emergence of language enclaves. The language enclave is formed because the speech community has a speech code that is different from the mother tongue and the nearest language. Language enclaves formed on the southern coast of Central Java occur at the level of internal innovation. Internal innovations in the southern coast language enclave occur in the form of allophones and allomorphs that can be traced based on the articulation process. Social heritage as a form of language preservation in the language enclave of the southern coast of Central Java is formed by the characteristics of simplicity and social intelligence of the people.
\end{abstract}

Keywords: Coastal environment; preservation; language enclave.

\section{Introduction}

Mental formation of humans is also, at least, affected by the surrounding environment, including the geographical condition of a cultural society. The more strategic an area, the higher the community mobilization is. The higher the mobilization of the speech community, the higher the culture acculturation will be. The more heterogeneous the culture of the community, the more diverse the language patterns of communication is. These cause the 
loss of local inheritance (linguicide) related to the language of the archipelago in a speech community which results in a decrease in the loyalty of speakers of the language.

As a chain of past civilizations in the south of Central Java, Cilacap, Kebumen, Purworejo have an extraordinary history of civilization. The history of civilization can be seen in the form of speech components. The speech component is reflected through the language used in these three large regions. Duranti (2009) states that linguistics have commonly uneasy about relying on vocabulary. He considers vocabulary to be the least significant part of a language. It is very unstable, widely from speaker and situation [1]. The terminology is in line with the condition of language which can obviously replace other languages or languages that are not displaced by other languages. The replaced language is a language that is unable to be preserved. In wave theory [2], certain language families move dynamically like waves. The waves will form a strong collision resulting in the extinction of a speech environment naturally or the wave forms a new speech environment. Like in the language enclave of Sundanese located on the southern coast of Central Java.

The unique facts in Cilacap, Kebumen, and Purworejo are that the areas have a different defence power than other regions. Administrative boundaries do not limit cultural acculturation. Therefore, in the three regions it is found cultural enclaves becoming special characteristics of a particular region. These cultural enclaves can be found in other areas that are not in the same administrative area. Cultural enclaves are also found in border areas, resulting in the tug of war between two different languages due to defending each other.

Portrait of language enclaves in the chain of past has never been revealed. This local wisdom can be used as a fundamental social policy in shaping the image of local languages in the eyes of the world. If the Javanese language of Solo Yogyakarta is full of good manners because of the diversity of speech level, so is the Javanese language of Cilacap-Banyumas which means simplicity as a reflection of solidarity and equality. Forms of language preservation must consider the pillars including: local policies, local intelligence, and local communities. The main and specific issues raised in this research are to examine the unique lexicon in the communities of Cilacap, Kebumen, and Purworejo through the reconstruction of speech components that reflect local intelligence in local communities, and subsequently local policies will be taken to strengthen local language preservation models. Local intelligence is strongly affected by local languages. Local languages form local identity and as a source of forming natural intelligence in the speech environment [3]. Geographical environment is a place to build personal and political identity, social relations of the speakers.

\section{Research Method}

This research was qualitative research. The research, which was oriented towards the reconstruction of speech components in the coastal communities of South Central Jawa, used a descriptive qualitative approach and a contextual approach. The speech component was analyzed using dialect geography and collaborated with the anthropological linguistic approach to find innovative models for the development and preservation of local identities.

The research location was on the southern coast of Central Java, which was a chain of past civilizations. The research location was focused on three districts; (1) Cilacap, (2) Kebumen, (3) Purworejo. The research location was focused on three districts. The research location was determined based on the determination process of the row of the Southern coast, as a chain of the past civilizations and the oldest in Central Java. (1) Cilacap, (2) Kebumen, (3) Purworejo. The three districts are administratively bordered by the Indian Ocean and are closely related to Sundanese culture, because the three districts are located on the border between two major provinces geographically: Central Java and West Java. So it is suspected to have a very high acculturation and it is very influential on the local identity of the local community, especially reflected in the form of speech. In detail, Cilacap District has a unique 
lexicon that is not possessed by other local languages. It is located on the border of the two provinces, causing a variety of forms of speech than Javanese language in other regions. Kebumen and Purworejo districts still have very thick Javanese spiritual power, bearing in mind that there was once a large civilization, the Majapahit Kingdom.

\section{Results and Discussion}

Language enclave is in which an area has a different speech environment from other regions even in the same geographical environment [4]. Enclave is part of a regional dialect. The culture of an area has a self-identity that characterizes it into an ethnicity, so that administrative boundaries do not limit the particular culture of a society including language. Therefore, it was not surprising if it was found cultural enclaves being characteristic of a particular region, but it could be found in other regions in different administrative region. Sometimes, these cultural enclaves also existed in border areas, resulting in the tug between the two different languages due to defending each other.

\subsection{Ecological Lexicon of Unique Identity in the Southern Coastal Communities of Central Java}

The identity of a community is due to its past environmental roles [3]. Past events leave a heritage forever. The heritage can develop according to the community strength. Community identity has a very close relationship to the social, cultural, and economic aspects of the speakers' community [5]. The speakers' community must not judge the community living on the border. Because cultural acculturation at the border provides local and global diversity. Community identity is not caused by administrative boundaries [3].

Unique identity can be seen in the Southern coastal communities of Central Java, which is reflected through the forms of ecological lexicon related to nature. These lexicons are found in the southern coastal environment of Central Java. As the southern coastal chain of Central Java bordering with West Java, the nuances of cultural acculturation as a form of cultural pluralism are very visible. Cultural acculturation results in the emergence of language enclaves. The language enclaves are formed because the speech community has a speech code that is different from the mother tongue and the nearest language. It is reflected in the following lexicon:

1) 'alir' (flow) in the lexicon's southern coastal dialect is reflected in 'mocor'.

In Sundanese, it becomes 'yocor'. Semantically, the two lexicon have the same meaning, but 'mocor' is not found in Javanese. Administratively, Cilacap is located in the Central Java.

2) 'asap' (smoke) in the southern coast dialect is reflected in 'haseub'.

'asap' in Sundanese is reflected in 'haseub'. Phonetic differences in the two lexicons are found in the pronunciation of phonemes /b/ soft voiced consonants and / $\mathrm{p} /$ voiceless hard consonants as the characteristic of Sundanese. The 'haseub' lexicon is not found in Javanese. There are phonological differences in the characteristics of Sundanese language phoneme with the coastal lexicon, it is assumed that the lexicon is internal innovation.

3) 'baik' (good) in the southern coast dialect is reflected in 'cageur'.

In Sundanese, it is pronounced "bageur." 'cageur' is not found in Javanese and it is not used in Sundanese. The lexicon is only used in the southern coast of Central Java. The difference in the lexicon does not occur in an articulatory environment that can be traced, the two lexicons are not the same form of allophones.

4) 'jemur' (dry in the sun) in the southern coast dialect is reflected in 'popoe'. 
'jemur' in Sundanese is reflected in 'moc'. Form of the lexicon in Sundanese has a complex form, 'panonpoc' meaning 'sun'. While 'matahari' (sun) in the coastal lexicon is reflected by 'matapoz'. 'matapoz' form of the lexicon can only be understood by the southern coast community of Central Java.

The dialect classification clearly shows that the southern coast has its own language code. Therefore, in the speakers' environment, it is naturally formed the enclave of language. The language enclave occurs because of language acculturation that forms new dialect innovations from influential dialects around it. Forms of innovation emerge, live, and develop together with older dialects [6].

\subsection{Social Heritage of the Southern Coastal Communities of Central Java}

One conceptualization of cultural heritage is manifested in language. The cultural diversity of the archipelago produces language variations. The conceptualization appears in:

1) Personality characteristics of the southern coastal community are warm, open to new things. It is manifested in the friendliness of one another. Friendliness is a form of plural society. These characteristics are very close to the coastal communities. Acculturation forms its own cultural system and values in its speaker environment. The community will not leave the established social order as a rule that has been mutually agreed upon as a social norm that must be obeyed together [7].

2) Intelligence is a characteristic that cannot be separated from coastal communities. Strategic environment makes coastal communities have more intelligence than others. Living in a coastal environment facilitates them to meet their daily needs, including meeting their economy. The intelligence in coastal communities is strongly affected by nature. Living near the beach makes them dependent on nature. Their subjection on nature appears in their habit of consuming fish. Fish are believed to form brain intelligence.

\section{Conclusion}

As the southern coastal chain of Central Java bordering with West Java, the nuances of cultural acculturation as a form of cultural pluralism are very visible. Cultural acculturation results in the emergence of language enclaves. Language enclave is formed because the speakers' community has a speech code that is different from the mother tongue and the nearest language. Language enclaves formed on the southern coast of Central Java occur at the level of internal innovation. Internal innovations in the southern coast language enclave occur in the form of allophones and allomorphs that can be traced based on the area of articulation. Social heritage as a form of language preservation in the language enclave of the southern coast of Central Java is formed by the characteristics of simplicity and social intelligence of the people. 


\section{References}

[1] Duranti, Alessandro. Linguistic Antrophology. British: Cambridge Text Books Publishers. ( 2009)

[2] Paul, Heggarty. Splits or Waces? Trees or Webs? How Divergences Measures and Nerwork Analysis Can Unravel Language Histories. (2010) http://www.jstor.com/stable/20789198

[3] Philip, Boland. Sonic Geography, Place and Race in The Formation of Local Identity: Liverpool and Scousers. (2020) http://www.jstor.com/stable/40835383

[4] Lauder, Multamia, RM. Pemetaan dan Distribusi Bahasa-Bahasa di Tangerang. Jakarta: Universitas Indonesia. (1990)

[5] Rutherford, Jonathan. A Place Laked Home: Identity and The Cultural Politics of Difference: in Rutherford, J. (ed): Identity Community, Culture, Difference. $2^{\text {nd }}$, Lawrence and Wishart. London. pp. 222-237 (1998)

[6] Alexander, M.S. Diachoric Dialect Classifications with Demonstratives. (2016) http://www.jstore.com/stable/26451377

[7] Suryadi \& Riris Tiani. The Influence of The Richness of Emotive Cultural Lexicon in Coloring The Politeness Form of Speech and Politeness Gradation of The Coastal Javanese Society in Pati District. E3S web of conferences 73, (2018)

https://doi.org/10.1051/e3sconf/20187308023 Icenis 2018 